\title{
O declínio organizacional e a ameaça de desemprego ao trabalhador
}

\author{
Organizational decline and the threat of unemployment for workers
}

\section{Déclin organisationnel et la menace par le chômage le travailleur}

\author{
El declive organizacional y la amenaza de desempleo al trabajador
}

\author{
Eveli Freire Vasconcelos ${ }^{1}$ \\ José Carlos Zanelli ${ }^{2}$ \\ Erico Renteria ${ }^{3}$ \\ Márcio Luís Costa ${ }^{1}$
}

Recebido em 20/06/2017; revisado e aprovado em 29/08/2017; aceito em 29/08/2017

DOI: http://dx.doi.org/10.20435/inter.v19i2.1633

\begin{abstract}
Resumo: Este artigo é uma revisão reflexiva da literatura especializada sobre declínio organizacional e ameaça ao desemprego, e tem como objetivo permitir uma visão geral sobre o tema, enfatizar a relevância do declínio nos estudos organizacionais, e distinguir a empregabilidade como forma alternativa de inserção social pelo trabalho. São propostas reflexões no sentido de contribuir na criação de estratégias tanto para a transformação da situação organizacional, quanto para a análise dos impactos aos trabalhadores.
\end{abstract}

Palavras-chave: declínio organizacional; ameaça de desemprego; insegurança no trabalho; empregabilidade.

Abstract: This article is a reflexive review of the specialized literature on organizational decline and the threat of unemployment, whose objective is to provide an overview on the subject, to emphasize its relevance in organizational studies, and to distinguish the employability as an alternative form of social insertion by the work. We proposed reflections to contribute to the creation of strategies that can contribute to the transformation of the organizational situation, as well as the analysis of the impacts and consequences on workers.

Keywords: organizational decline; unemployment threat; job insecurity; employability.

Résumé: Cet article constitue une révision réfléchie de la littérature spécialisée sur le déclin organisationnel et la menace par le chômage, dont l'objectif est de permettre une vision générale sur le sujet, de souligner son importance dans les études organisationnelles, et de distinguer l'employabilité comme forme alternative d'insertion sociale par le travail. Ce sont de proposition pour contribuer à la création de stratégies pour la transformation de la situation organisationnelle, et pour l'analyse des impacts chez les travailleurs.

Mots cles: déclin organisationnel; menace de chômage; insécurité au travail; employabilité.

Resumen: Este artículo es una revisión reflexiva de la literatura especializada sobre declive organizacional y la amenaza por el desempleo, cuyo objetivo es posibilitar una visión general sobre el tema, enfatizar su relevancia en los estudios organizacionales, y distinguir la empleabilidad como forma alternativa de inserción social por el trabajo. Son propuestas para contribuir en la creación de estrategias para la transformación de la situación organizacional, y para el análisis de los impactos en los trabajadores.

Palabras claves: declive organizacional; amenaza de desempleo; inseguridad en el trabajo; empleabilidad.

\section{INTRODUÇÃO}

As transformações socioeconômicas que ocorreram no Brasil nos últimos anos rapidamente se estenderam e afetam praticamente todos os setores de atividade do país. Também é possível identificar o fechamento de empresas e o aumento do desemprego, que vem acompanhando as mudanças macroambientais do país. Rentería (2008) argumenta que o aumento na taxa de desemprego origina-se pelo declive das organizações de trabalho e discute que o tempo de sobrevivência de uma empresa depende não apenas da gestão dos seus administradores, mas

\footnotetext{
${ }^{1}$ Universidade Católica Dom Bosco (UCDB), Campo Grande, Mato Grosso do Sul, Brasil.

${ }^{2}$ Universidade Federal de Santa Catarina (UFSC), Florianópolis, Santa Catarina, Brasil.

${ }^{3}$ Universidad del Valle, Cali, Colombia.
} 
também do momento em que se encontra o país, sua economia, ressaltando a importância do governo para a manutenção das companhias, questões essas identificadas como problematizadoras de estudo. Todavia o declínio organizacional e a ameaça de desemprego devem ser objetos de reflexão para os estudiosos, mas também para os membros das organizações (SALLES, 2015; SERRA, FERREIRA; ALMEIDA, 2013; THIRY-CHERQUES, 1991; TORRES, 2010).

Assim, este ensaio apresenta uma revisão sobre o declínio organizacional e ameaça ao desemprego, apresentando um levantamento das pesquisas teóricas e empíricas que abarcam publicações sobre o assunto. Realiza, também, uma análise sobre a evolução dos temas pesquisados e apresenta propostas para futuras pesquisas no assunto. Os eventos associados ao desemprego tornam-se fenômenos ameaçadores. Resultam em redução das expectativas de vida organizacional e consequente ameaça ao trabalhador. Situações experimentadas por este como inseguras e de grande tensão, geradas pela impotência diante do prenúncio da não continuidade da vida organizacional (RENTERÍA, 2012).

\section{DECLÍNIO ORGANIZACIONAL}

As teorias sobre o ciclo de vida organizacional são utilizadas para esclarecer as diferentes fases de uma organização, que podem ir desde sua concepção até a sua morte, um conceito adaptado das ciências biológicas que permite reconhecer o percurso de uma organização e a interação desta com o ambiente em seus distintos estágios de evolução. Adizes (1996) argumenta que o ciclo de vida pode ser utilizado para entender o desenvolvimento organizacional. Assim, observa-se que as organizações, apresentam características de nascimento, crescimento e declínio (morte).

Os pesquisadores sobre ciclo de vida organizacional utilizam distintas terminologias para categorizar as diferentes perspectivas. Adizes (1996) descreve o ciclo como sendo constituído por dez estágios, agrupados em três níveis, com características bem específicas. O primeiro nível é denominado de estágio de nascimento; o segundo, de crescimento ou maioridade; e o terceiro, de envelhecimento podendo se estender até a morte. Todavia o modelo de Lester, Parnell e Carraher (2003) propõe cinco estágios, sendo o primeiro de existência; o segundo de sobrevivência; o terceiro de sucesso; o quarto de renovação; e o quinto de declínio. As definições para cada um desses estágios tornam-se aplicáveis a todos os tipos de "organismos" e está em conformidade com o corpo de literatura sobre ciclo vital.

Assim, além de reconhecer o declínio como uma das fases do ciclo, é possível identificá-lo como um conjunto de atividades separadas, pois várias empresas experimentaram períodos de declínio em determinados estágios (LESTER; PARNELL; CARRAHER, 2003). O declínio organizacional pode ter diversas origens sendo uma delas a própria organização, por motivos como custos, redução da força de trabalho e/ou decadência nos ganhos (GREINER, 1972). As pesquisas realizadas sobre o tema, geralmente, acontecem com empresas que já desfrutaram de sua existência, sobrevivência e até sucesso.

As fusões e aquisições são casos específicos, nos quais certas empresas são preservadas, muitas vezes, de morte iminente. As consequências para os trabalhadores que permanecem na empresa adquirida são os desgastes da adaptação ao novo contexto cultural, quando se trata de aquisição - sem aqui detalhar os cortes de pessoal comuns nessas situações. Na perspectiva psicossocial, as fusões não são muito diferentes para os trabalhadores. Contudo, ainda nesses casos, é possível não só a identificação de consequências, quanto à previsão e projeção de 
ações na "gestão do declínio" (RENTERÍA, 2012) e no desenvolvimento da empregabilidade dos trabalhadores (RIOS; TEIXEIRA, 1997) e outras implicações para com eles.

Portanto identificar as condições que promovem o declínio nos diferentes estágios nos remete a Greiner (1972); o autor considera que o declínio depende das respostas da organização aos problemas inerentes aos estágios e argumenta que da mesma forma que acontece com os seres humanos, as passagens da infância para a adolescência e desta para a maturidade podem ser tempestuosas e marcadas por crises e turbulências.

Ao ressaltar a importância do nascimento, assim como da morte para as organizações, Salama (1994) ainda destaca a gestação, concepção ou o trauma de nascimento como profícuos para a vida das empresas, considerando que as condições de primeira infância podem determinar o desenvolvimento posterior de maneira significativa, tanto às pessoas quanto às organizações. Fleck (2004) argumenta que resultados empíricos indicam que os traços do início de vida organizacional tendem a influenciar o seu desenvolvimento e autoperpetuação.

Para Torres et al. (2008), as empresas costumam seguir um ciclo de vida mais ou menos determinístico o que, eventualmente, conduzirá à morte, em que o declínio surge como algo inevitável. Isso também pode surgir como reflexo da estagnação ou da redução, podendo ser originária do mercado, do aumento da competição, da não adaptação a um nicho ou a clientes da própria organização, ou mesmo da ausência de adaptação à mudança organizacional. Essa falta de adaptação ao ambiente é discutida como uma falha grave, uma vez que o ambiente influencia muito nas tomadas de decisão (CARVALHO, 2013). Embora existam diferentes causas de declínio, as organizações são substancialmente e materialmente impactadas e podem enfrentar consequências a curto prazo, tais como o fluxo de caixa líquido negativo, e resultados a longo prazo, tais como falência ou morte organizacional.

Madeira (2003) apresenta quatro fases do declínio, sendo estas: o desenvolvimento, o reconhecimento, a resposta e o resultado, considerando que "a degradação torna-se oficial com a ocorrência da crise financeira" (MADEIRA, 2003, p. 192). Entretanto, para o autor, não existe consenso quanto à definição de declínio. Para Carvalho (2013, p. 29): "declínio organizacional é um fenômeno de longo prazo recorrente da inabilidade da organização mudar e se adaptar, mas sobretudo do encolhimento dos recursos internos". Dessa maneira, entende-se por declínio organizacional, um período de turbulência causado pelo risco de extinção da organização, a partir de múltiplas causas. As alterações do ambiente interno associadas à instabilidade, relacionam-se diretamente às mudanças que acabam por ocorrer em detrimento das dificuldades, em que a ausência de recurso financeiro surge como evidência básica.

Torres et al. (2008) consideram, ainda, a existência de uma polêmica teórica sobre o assunto. Levy (1986) ressalta a falta de discernimento e conhecimento sobre as ameaças ambientais e limitação organizacional, inclusive para instaurar ações corretivas. Weitzel e Jonsson (1989) discutem o início do declínio na falta do reconhecimento antecipado das ameaças externas que impedem a manutenção da sobrevivência. Discute-se que o declínio tem início quando cessam os recursos financeiros; assim, Salles (2015) classificou o conceito de declínio em quatro grupos: deterioração em recursos, deterioração em desempenho, deterioração da capacidade de se adaptar ao ambiente externo e interno, e uma fase do ciclo vital. Entrar em declínio não necessariamente significa falir ou paralisar suas atividades, sendo que, em todas as fases, é possível retomar o desempenho, apenas na última fase (fase de dissolução) a recuperação não é mais eficaz. 
Enquanto alguns pesquisadores, concentraram-se no conceito e definição de declinio, outros desenvolveram modelos teóricos que descrevem o ambiente de mudanças responsáveis pelo declínio organizacional e os impactos desse fenômeno na estrutura organizacional. Na realidade, não se entende ainda de fato o que leva as empresas a declinarem, o que pode estar relacionado à falta de estudos empíricos (SERRA; FERREIRA; ALMEIDA, 2013). Segundo Mone, Mckinley e Barker (1998), alguns estudos empíricos examinaram as consequências reais e percebidas do declínio.

O declínio organizacional tem sido tratado sob muitas perspectivas na literatura; a expansão (crescimento) e declínio nas organizações fazem parte do que pode ser chamado de dinâmica organizacional, mas a expansão foi abordada por muitos autores como um estado organizacional normal, enquanto as discussões sobre declínio só emergiram no final dos anos 1970 e início dos anos 1980, como uma importante condição organizacional, período esse característico pelo início da reestruturação produtiva e de desmonte do estado social de proteção em muitos países ocidentais que acabaram também por influenciar essas discussões.

O estudo empírico de declínio é muito mais difícil porque os profissionais que vivem o declínio têm pouco ou nenhum interesse em pesquisa, visto que sua preocupação é a sobrevivência, mas seu estudo apresenta-se como de fundamental importância, considerando as sérias consequências sociais resultantes das interrupções para a economia e para os indivíduos dependentes das organizações que declinaram (WEITZEL; JONSSON, 1989).

As abordagens existentes não delineiam claramente as condições em que o declínio ocorre, nem identificam totalmente os sinais, também não nos apresenta uma resposta quanto ao reconhecimento do declínio (WEITZEL; JONSSON, 1989). Levy (1986), focado na compreensão da dinâmica de transições organizacionais e transformações radicais dos sistemas humanos, explora e examina as mudanças nas organizações. Para o autor, declínio é uma fase em que são externadas as necessidades de mudanças e na qual se descobre que os sinais de avisos foram ignorados, levando o sistema a atingir um ponto crítico para além do qual a alternativa é morte ou revitalização. Parece-nos decisivo, assim, que a organização de trabalho acompanhe e avalie as características e necessidades de mudança, com sistemático acompanhamento de suas respostas ao ambiente e ao mercado.

D’Aveni (1989), em um estudo longitudinal, realizou comparações entre uma amostra composta de 49 grandes empresas falidas e 49 sobreviventes, sendo estas de tamanho proporcional, estudadas duas a duas. Para cada par, os dados foram coletados durante os cinco anos anteriores à falência. As empresas foram selecionadas aleatoriamente dentre aproximadamente 1.000 por tamanho de vendas e falências que ocorreram entre 1972 e 1982, nos setores de varejo e transporte da economia nos Estados Unidos da América. As empresas foram classificadas em empresas falidas, de acordo com o seu padrão longitudinal de declínio sobre os últimos cinco anos de existência, e comparadas com os resultados de pós-declínio das empresas sobreviventes, avaliando as consequências do declínio. Os resultados apontados apresentam a existência de diferentes padrões de declínio, com consequências como desequilíbrio gerencial, centralização e paralisação estratégica, que surgem como respostas à rigidez organizacional e à própria ameaça de declínio, mas apesar dos efeitos adversos, D’Aveni (1989) acredita que a falência pode ser retardada ou mesmo evitada em um ambiente de crescimento. As organizações de trabalho são entidades sociais artificiais, criadas para produzir resultados (RENTERÍA, 2012), e que não são organismos no sentido fisiológico. Nessa ordem de ideias, a possibilidade de redirecionamento ou de recriar-se existe. 
A metáfora do cérebro utilizada por Morgan (1986) auxilia na compreensão da organização como um sistema cognitivo, corporificando tanto a estrutura de pensamento, como o padrão de ações, enquanto que, nas teorias tradicionais, a atenção tem sido devotada ao modo pelo qual os elos de comunicação são estabelecidos entre os diferentes componentes organizacionais. Carmeli e Schaubroeck (2006) examinaram o papel da integração das equipes de gestão para explicar a qualidade das decisões estratégicas e como essas construções podem influenciar o declínio organizacional. Um estudo de caso demonstrou que, quando os membros da equipe relatam uma maior integração comportamental, as decisões estratégicas são de melhor qualidade; já a integração comportamental foi negativamente relacionada com declínio, pela qualidade das decisões estratégicas. Os autores discutem as implicações para a utilização mais plena da capacidade da equipe para confrontar ameaças organizacionais, e evidenciam que poucos estudos já exploraram a influência dos processos grupais no declínio organizacional.

Para Torres (2010, p. 44), "no Brasil, existem poucas pesquisas especificamente sobre o tema declínio ou falha organizacional". Mas constata-se um estudo de caso, com perspectiva longitudinal, que buscou identificar e analisar os fatores de declínio do Banco Bamerindus entre 1980 e 1997. Os autores Roiek e Bulgacov (1999) utilizaram o método descritivo-qualitativo para a análise de fatores contextuais de alguns processos estratégicos de declínio, a comprovação foi alcançada mediante a triangulação metodológica, com entrevistas abertas e semiestruturadas, jornais, revistas especializadas, índices econômicos e publicações. Nesse estudo, pôde-se concluir que, de fato, a fase de declínio do Bamerindus foi caracterizada por fatores críticos ambientais e do processo estratégico, que influenciaram o seu desempenho e atuação.

O declínio pode acarretar consequências severas, tanto interna quanto externamente à organização, desde gerar e/ou agravar os conflitos interpessoais até influenciar o meio familiar dos trabalhadores, podendo deixar marcas profundas em todos os envolvidos (TORRES, 2010). Se, por um lado, o declínio organizacional representa uma lacuna entre o desempenho e aspirações, e os teóricos da aprendizagem organizacional sugerem que o declínio estimula os processos de adaptação, de busca, e mudança organizacional, por outro lado, também sugerem que o declínio inibe processos cognitivos, restringindo a tomada de decisão e limitando o número de opções (MONE; MCKINLEY; BARKER, 1998). Os eventuais danos ou custos sociais inerentes ao desaparecimento de organizações interessa não somente a seus dirigentes e aos titulares de capital, mas também, aos variados atores e agentes sociais que compõem o ambiente, pois o tema alcança diferentes categorias de usuários (VASCONCELOS, 2007). As definições de declínio estão relacionadas aos seus efeitos que, em outras circunstâncias, não oferecem meios para um diagnóstico preciso.

A economia em transição provoca efeitos complexos e significativos sobre as empresas; como consequência, as forças mais importantes desse contexto irão interagir e confrontar as variáveis de base (socioeconômica e política) e formar esquemas cognitivos que orientam o comportamento do indivíduo. A inépcia de uma organização em declínio é considerada nos estudos, visto que é equivalente a ser doente num modelo orgânico (ROIEK; BULGACOV, 1999), o que, metaforicamente, implicaria um tratamento à base de investimento financeiro e humano, e, para a eficácia do tratamento, torna-se necessário conhecer como as pessoas internalizam esses processos e desenvolvem conhecimentos - como já indicado. Morgan (1986) ao referir-se à metáfora da organização como prisão psíquica -, útil para o gerenciamento de operações de negócios em economias transitórias, nos permite incorporar que, junto ao declínio, os atores vivem também a real ameaça de desemprego. 


\subsection{A ameaça de desemprego e a fragilização durante o declínio}

Para Jick e Greenhalgh (1981), os trabalhadores captam os sinais de declínio, por anúncios oficiais característicos de período de mudanças organizacionais, pela identificação de questões que parecem não mediadas ou negligenciadas por níveis hierárquicos superiores, e pelos rumores, abundantes, especialmente quando as informações e comunicações oficiais são escassas. O que o indivíduo percebe como perda na situação de trabalho é o que se estende à perda permanente do próprio trabalho e à perda de alguma característica subjetiva importante do trabalho (GREENHALGH; ROSENBLATT, 1984). Tal conhecimento é crucial porque essa experiência da ameaça ao desemprego, com a consequente insegurança, são elementos-chaves na aceleração do declínio organizacional.

Frente às tendências de mercado cada vez mais imprevisíveis e flexíveis, presume-se que os trabalhadores tendem a sustentar a ameaça ao desemprego de forma mais constante, mantendo sentimentos de insegurança. Pensando nessas questões, De Cuyper et al. (2010) investigaram a ameaça objetiva de desemprego e insegurança quanto à situação de trabalho, assim como a tensão associada, após a reestruturação de uma organização de serviços belga que tinha recentemente anunciado sua intenção em reduzir seu tamanho; a amostra foi composta por cento e vinte e dois trabalhadores e constatou-se que a ameaça objetiva de desemprego estava presente em trabalhadores que foram informados sobre a demissão. A incerteza da situação foi elevada entre profissionais em que a decisão sobre a demissão estava pendente. Houve uma baixa ameaça de desemprego e reduzida incerteza quanto à situação nos trabalhadores que foram informados que seus empregos estavam seguros.

Kinnunen e Nätti (1994) realizaram um estudo em 1990 com objetivo de examinar a prevalência, antecedentes e consequentes da insegurança no trabalho, em uma amostra de assalariados finlandeses, um a cada dez inquiridos, considerava a ameaça de despedimento ou desemprego. De acordo com a análise de regressão hierárquica, a insegurança no trabalho percebida foi mais bem explicada por fatores posicionais, especialmente experiências de desemprego anteriores e a natureza temporária da relação de trabalho. Os fatores demográficos apresentam uma menor influência na insegurança. As análises de regressão confirmaram os efeitos negativos da insegurança no trabalho percebidos na saúde e já encontrados em estudos anteriores. O suporte social encontrado tem efeito moderador, pois alivia os efeitos negativos da insegurança no trabalho. Assim, a insegurança no trabalho foi um estressor psicológico com consequências negativas para uma proporção considerável dos empregados.

Castell (2009) argumenta que, para o ser desempregado, haverá incertezas quanto ao seu futuro profissional, pois tornaram-se alvo de discriminação e exclusão. O autor discute que o distanciamento do meio social tende a provocar rupturas nos laços de sociabilidade que foram construídos no mundo do trabalho (BLANCH-RIBAS, 2003). A investigação sobre as consequências psicológicas da insegurança no trabalho vem avançando. Demonstra que a insegurança em relação ao emprego reduz o bem-estar psicológico, a satisfação no trabalho e aumenta queixas psicossomáticas.

As condições de trabalho caracterizadas pela incerteza e ambiguidade são potenciais fatores estressores para os funcionários, pela insegurança provocada pela situação (VESGA, 2016). Dekker e Schaufeli (1995), ao apresentar os resultados da pesquisa sobre os efeitos da insegurança no trabalho, descrevem que ela está associada à deterioração da saúde psicológica. Fica marcada a predisposição a manifestações comportamentais de baixo esforço, resistência à 
mudança e propensão a sair do emprego, como características dos trabalhadores que também parecem iniciar o processo de luto antecipadamente à perda do emprego, como se existisse uma retirada psicológica (JICK; GREENHALGH, 1981). Para Vasconcelos (2016), pesquisas atuais sustentam o interesse em compreender as representações que os trabalhadores têm de uma experiência profissional na qual houve o declínio organizacional e, por consequência, se manteve a ameaça ao desemprego, assim como sobre um dos fenômenos que mais tem inquietado a sociedade atual - o desemprego.

\subsection{O Desemprego e a empregabilidade}

De acordo com Dejours (1992), o desempregado possui uma imagem negativa na sociedade. Há um distanciamento do meio social, com rupturas dos laços de sociabilidade que foram construídos no mundo do trabalho. Nessa perspectiva da sociabilidade, Jacques (2003) esclarece que a ruptura social advinda do desemprego permeia o afastamento do sujeito das principais referências de seu cotidiano. O desemprego implica um problema de exclusão social pelo trabalho e a mudança de uma boa parte dos referenciais na e da organização social e pessoal, assim como a construção da própria identidade das pessoas (MALVEZZI, 2000; RENTERÍA, 2009; RENTERÍA; MALVEZZI, 2008).

Compreende-se, a partir do exposto, que, para a sociedade atual, o trabalho é mais que trabalho, e o não-trabalho é mais que desemprego (CHAUÍ, 2000), passando provavelmente para a empregabilidade como referente (RENTERÍA, 2012; 2016; RENTERÍA; MALVEZZI, 2008). O medo da falta de emprego, pelo sentimento de exclusão, faz com que se torne possível para o sujeito suportar trabalhar em condições precárias e aceitando baixos salários. Os trabalhadores buscam estratégias de sobrevivência e recolocação no trabalho a qualquer custo, comportamentos ocasionados por esse processo de desvalorização social do desemprego (AZEVEDO et al., 1998). Pinheiro e Monteiro (2007), ao reconhecerem o desemprego como grande influência na condição subjetiva do trabalhador, relatam que podem surgir dois polos nessa situação: de um lado, aqueles trabalhadores à procura de emprego em tempo integral e, de outro, aqueles trabalhadores "desmotivados" ou "desalentados" (GLEJBERMAN, 2012), que já não procuram mais emprego.

Jahoda (1988) propõe um modelo que parte da concepção de que o desemprego priva o indivíduo de vários ganhos, tais como os benefícios da remuneração, uma função manifesta do emprego, sem contar mais cinco funções ocultas: a estruturação temporal do cotidiano; contatos com pessoas fora da família; metas e propósitos que transcendem o individual; status; e identidade. A autora enfatiza que a principal característica comum a todos os que se encontram desempregados é a exclusão abrupta de uma instituição social, a qual dominava ou "regrava" boa parte de suas vidas anteriormente.

Em discussão similar Blanch-Ribas (2003) apresenta a complexidade da relação homem trabalho e discorre sobre a importância das condições socioeconômicas; para o autor é importante considerar o cenário de diversificação e complexidade nas quais a ação humana se desenvolve, e sobre o significado e valor sociocultural dessas novas experiências. Rentería (2016) ressalta a dimensão social como um marco para se pensar em ações em saúde e trabalho, assim como os efeitos do emprego e/ou desemprego no bem-estar e qualidade de vida.

De acordo com Witte, Hooge e Vanbelle (2010), estudos longitudinais têm apontado o impacto negativo do desemprego sobre o bem-estar psicológico. Ao reverem as evidências em 
uma variedade de países, identificam um padrão típico a ser observado: numa primeira fase, o bem-estar psicológico dos desempregados apresenta uma forte diminuição, pois inicialmente é um período de muitas incertezas, mas, depois de um tempo, a rotina e as expectativas vão se tornando mais claras, o que reduz a tensão causada pela incerteza. Como consequência, o bem-estar psicológico se estabiliza, mas em um nível inferior ao do empregado, havendo uma familiarização e/ou adequação à situação.

Para Rose e Harris (2004), pessoas desempregadas têm sua saúde psicológica e seu bemestar significativamente mais pobres do que as pessoas que estão na força de trabalho. A pobreza na saúde psicológica citada pelos autores significa baixa motivação e expectativas em encontrar um trabalho ou um emprego eficaz. O segundo componente relatado na pesquisa de Witte, Hooge e Vanbelle (2010) se refere ao processo de adaptação. O desemprego é uma experiência frustrante, principalmente quando se está fortemente focado em encontrar um emprego. Depois de certo tempo, os desempregados sentem que é muito difícil, talvez impossível, encontrar um emprego, e isso exige deles o desenvolvimento de uma estratégia de enfrentamento específica para lidar com a situação. Quanto maior o compromisso da pessoa em encontrar um emprego e não consegui-lo, maior é a frustração, levando a um aumento do sofrimento psíquico e, muitas vezes, à redução na procura de emprego caindo na condição de "desmotivado" ou "desalentado". O tempo de duração do desemprego e outras variáveis demográficas tais como sexo, idade e nível de educação também influenciam a experiência de desemprego e os níveis de bem-estar psicológico (WITTE; HOOGE; VANBELLE, 2010), assim como a empregabilidade das pessoas na medida em que configuram "características problemáticas" (RENTERÍA; MALVEZZI, 2008)

Nessa ordem de idéias, a questão da empregabilidade como uma estimativa ou medida relativa de inclusão por e no mundo do trabalho, passaria a ter um papel diferente no caso das empresas em declínio. Por um lado, representa a possibilidade de evitação do desemprego, caso as pessoas continuem e a empresa não falhe, ou ainda, saindo, possam continuar no mercado de trabalho; e por outro, a empregabilidade como indicador de "trabalhadores" de diversos níveis das organizações capazes de lerem contextos e responderem aos requerimentos para se manter nelas, e que as próprias organizações possam se manter (RENTERÍA, 2012). Isto é, a empregabilidade como uma questão que extrapola a dimensão individual e passa a representar uma questão ainda de responsabilidade organizacional.

A consideração da interface entre quatro dimensões é chave na busca da empregabilidade como opção ao desemprego no caso do declínio organizacional em qualquer uma das etapas ou ciclos. Por um lado, trata-se de uma questão que afeta os trabalhadores no plano individual, mas não se limita a esse nível na medida em que tem, como condições, a observação de outras dimensões de ordem do contextual social, do contexto organizacional ou das relações de trabalho; assim como dos dispositivos de preparação a formação (BOTERO; RENTERÍA, no prelo). Essa última dimensão é provavelmente na que se instaura uma chance de preparação para se defrontar com as demandas da ameaça ao desemprego por uma disposição para refletir e desenvolver a empregabilidade, o que não pode cair sob os ombros das pessoas quando o declínio é um processo igualmente multidimensional. De alguma maneira, trata-se de reconhecer que a ameaça ao desemprego nesses casos, e a fragilidade das relacões de trabalho não são um problema individual, e sim causado na interface entre as possibilidades individuais, e as condicões das estruturas (FORRIER; SELS; STYNEN, 2009) nas quais se gestou o declínio. 


\section{CONSIDERAÇÕES FINAIS}

As condições de sucesso, bem como as de insucesso de uma organização de acordo com Vasconcelos (2007), não podem ser reproduzidas para dimensionamento do efeito das variáveis do declínio; no entanto nos parece relevante identificar como os trabalhadores esquematizam o conhecimento sobre a experiência de trabalho em uma organização que está declinando ou declinou. O momento atual evidencia e enfatiza a força desestabilizadora das crises financeiras, declínios ou reestruturações. Apontar os efeitos cognitivos e emocionais da experiência, da crise e do declínio sobre os atores organizacionais pode nos sugerir a direção tomada pelo trabalhador em face à adversidade e futuras expectativas frente à necessidade de reinserção no mercado de trabalho.

Fugate, Kinicki e Ashforth (2004) sugerem trabalhos contínuos de gerenciamento de mudanças, para sobrevivência nesses ambientes turbulentos. Para os autores, deve existir uma construção psicossocial centrada em auxiliar os trabalhadores de forma eficaz. Em primeiro lugar, os funcionários devem obter informações adequadas sobre o seu ambiente; em segundo lugar, precisam possuir condições internas apropriadas para a adaptabilidade, assim como para a aquisição de conhecimentos, habilidades, capacidades e cognições (esquemas, por exemplo), para permitir a negociação dos muitos desafios internos e externos de mudança. Bastos et al. (2011) definem como embrionárias também as pesquisas acerca da associação entre estrutura cognitiva de trabalhadores e diferentes estágios organizacionais. Porém, além dos autores referidos, existem algumas reflexões que já consideram essas interfaces e a configuração de repertórios cognitivos e de atuação adequadas para ler não somente o desemprego e a empregabildiade (FORRIER; SELS; STYNEN, 2009; RENTERÍA, 2012), mas o próprio declínio dos atores envolvidos, ainda que não conscientemente.

A Psicologia Organizacional e do Trabalho (POT) reconhece os desafios impostos às organizações e aos trabalhadores num momento como o de declínio organizacional, assim como os fenômenos psicossociais inerentes a esse período. Mas a sobrevivência de ambos (organização e trabalhadores) requer a passagem de um estado presente a outro de revitalização ou alavancagem que demanda mudança (ZANELLI, 2015). Dessa forma, a renovação organizacional e a busca do reequilíbrio também requerem mudanças que são alicerçadas pelos modelos mentais (visões de mundo) dos atores e gestores organizacionais, ancorados em crenças pessoais arraigadas (ZANELLI, 2015).

Representações mentais que configuram os repertórios que já não podem acomodar ou explicar ocorrências do ambiente, e novas compreensões devem ser desenvolvidas para adaptação individual e organizacional eficaz, que vão desde uma reconfiguração cultural, estrutural e funcional dos processos e da organização até as cognições e emoções. Para Zanelli (2015, p. 464), "compreendidas de modo simples como disposições ou probabilidade de uma pessoa agir na direção proposta". Estudos e intervenções que consideram a situação de declínio, principalmente em meio a situações difícieis, como a que o país vive atualmente, são escassos. Identifica-se, inegavelmente, grande parte das organizações de trabalho e dos trabalhadores expostos e suscetiveis às influências que podem configurar riscos à saúde e à sobrevivência de ambas as partes (RIOS; TEIXEIRA, 1997).

A necessidade de uma revisão política e da economia do país demonstra um desequilíbrio sem precedentes no mercado, noticiada diariamente. Os efeitos desse cenário vêm sendo discutidos como insalubres às organizações e aos trabalhadores, mas encontramos espaços para 
conhecer a dinâmica intrínseca compartilhada entre os atores nos diversos estágios e cenários organizacionais. O difícil momento, requer um entendimento mais aprofundado dos mecanismos que entram em cena quando ocorrem transformações ou dificuldades organizacionais, questão essa que impõe a necessidade urgente de se incrementar estudos referentes ao declínio organizacional, seus efeitos e impactos ao trabalhador.

\section{REFERÊNCIAS}

ADIZES, I. Os ciclos de vida das organizações. São Paulo: Pioneira, 1996.

AZEVEDO, J. T. et al. As estratégias de sobrevivência e de busca de emprego adotadas pelos desempregados. Cadernos de Psicologia Social do Trabalho, São Paulo, v. 1, n. 1, p. 15-42, 1998.

BASTOS, A. V.; SOUZA, J. J.; COSTA, V. M.; PEIXOTO, A. L. A adoção de novas práticas de gestão: explorando o esquema cognitivo dos atores em empresas com diferentes padrões de inovação. Revista de Ciências da Administração, Florianópolis, v. 13, n. 31, p. 243-78, set./dez. 2011.

BLANCH-RIBAS, J. M. Trabajar en la modernidad industrial. In: TOMÁS, M. J.; DURÁN, C. G.; ARTILES, A. M.; BLANCH-RIBAS, J. M. (Ed.). Teoría de las relaciones laborales: fundamentos. Barcelona: Editorial UOC, 2003. p. 19-147.

BOTERO, J.; RENTERÍA, E. Empleabilidad y trabajo del profesorado universitario: una revisión del campo. No prelo.

CARMELI, A.; SCHAUBROECK, J. Top management team behavioral integration, decision quality, and organizational decline. The Leadership Quarterly, v. 17, n. 5, p. 441-53, out. 2006.

CARVALHO, K. L. Uma proposta para o diagnóstico do declínio organizacional. 2013. Tese (Doutorado em Engenharia) - Universidade de São Paulo (USP), São Paulo, 2013. Disponível em: <http://www.teses.usp. br/teses/disponiveis/3/3136/tde-07062014-121156/>. Acesso em: 23 dez. 2015.

CASTELL, R. Las metamorfosis de la cuestión social: una crónica del salariado. Buenos Aires: Paidós, 2009.

CHAUÍ, M. Convite à filosofia. São Paulo: Ática, 2000.

D'AVENI, R. A. The aftermath of organizational decline: a longitudinal study of the strategic and managerial characteristics of declining firms. The Academy of Management Journal, v. 32, n. 3, p. 577-605, set. 1989.

DE CUYPER, N.; DE WITTE, H.; ELST, T.; HANDAJA, Y. Objective threat of unemployment and situational uncertainty during a restructuring: associations with perceived job insecurity and strain. Journal of Business and Psychology, v. 25, n. 1, p. 75-85, mar. 2010.

DEJOURS, C. A loucura do trabalho: estudo em psicopatologia do trabalho. São Paulo: Cortez/Oboré, 1992.

DEKKER, S.; SCHAUFELI, W. The effects of job insecurity on psychological health and withdrawal: a longitudinal study. Australian Psychologist, v. 30, n. 1, p. 57-63, 1995.

FLECK, D. L. Crescimento, dominância continuada e declínio da empresa: insights das histórias da General Electric e da Westinghouse. Revista de Administração Contemporânea, edição especial, p. 79-106, 2004.

FORRIER, A.; SELS, L.; STYNEN, D. Career mobility at the intersection between agency and structure: a conceptual model. Journal of Occupational and Organizational Psychology, v. 82, n. 4, p. 739-59, 2009.

FUGATE, M.; KINICKI, A. J.; ASHFORTH, B. E. Employability: a psycho-social construct, its dimensions, and applications. Journal of Vocational Behavior, v. 66, n. 1, p. 14-38, ago. 2004.

GLEJBERMAN, D. Conceptos y definiciones: desempleo y personas fuera de la fuerza de trabajo. Turín: Departamento de Estadística de la OIT. 2012. Disponível em: <http://recap.itcilo.org/es/documentos/ files-imt2/es/dg6>. Acesso em: 20 jan. 2017.

GREENHALGH, L.; ROSENBLATT, Z. Job insecurity: toward conceptual clarity. The Academy of Management Review, v. 9, n. 3, p. 438-48, jul. 1984. 
GREINER, L. R. Evolution and revolution as organizations grow. Harvard Business Review, v. 50, n. 4, p. 1-11, 1972.

JACQUES, M. G. Abordagens teórico-metodológicas em saúde, doença mental e trabalho. Psicologia \& Sociedade, Belo Horizonte, v. 15, n. 1, p. 97-116, jan./jun. 2003.

JAHODA, M. A recessão econômica e saúde mental: algumas questões conceituais. Jornal de Questão Social, n. 44, p. 13-23, 1988.

JICK, T. D.; GREENHALGH, L. Information processing of new recruits in a declining organization. Paper apresentado na Annual Meeting of the Academy of Management. San Diego, CA, 1981.

KINNUNEN, U.; NÄTTI, J. Job insecurity in Finland: antecedents and consequences. European Work and Organizational Psychologist, v. 4, n. 3, p. 297-321, 1994.

LESTER, L. D.; PARNELL, J. A.; CARRAHER, S. Organizational life cycle: a five-stage empirical scale. International Journal of Organizational Analysis, v. 11, n. 4, p. 339-54, 2003.

LEVY, A. Second-order planned change: definition and conceptualization. Organizational Dynamics, v. 15, n. 1, p. 5-20, 1986.

MADEIRA, P. Falência ou recuperação empresarial como resultado do declínio organizacional: uma estrutura conceptual explicativa. GESTIN, Castelo Branco, Portugal, ano 2, n. 2, p. 191-206, dez. 2003. Disponível em: <http://repositorio.ipcb.pt/bitstream/10400.11/235/1/PauloMadeira191-206Documento\%20do\%20 Microsoft\%200ffice\%20Word.pdf>. Acesso em: 23 dez. 2015.

MALVEZZI, S. A construção da identidade profissional no modelo emergente de carreira. Organizações \& Sociedade, Salvador, BA, v. 7, n. 17, p. 137-43, jan./abr. 2000. Disponível em: <http://www.scielo.br/scielo. php?script=sci_arttext\&pid=S1984-92302000000100011\&lng=en\&nrm=iso>. Acesso em: 23 dez. 2015.

MONE, M. A.; MCKINLEY, W.; BARKER, V. L. Organizational decline and innovation: a contingency framework. The Academy of Management Review, v. 23, n. 1, p. 115-32, jan. 1998.

MORGAN, G. Images of organization. Newbury Park, CA: Sage Publications, 1986.

PINHEIRO, L. R.; MONTEIRO, J. K. Refletindo sobre desemprego e agravos à saúde mental. Cadernos de Psicologia Social do Trabalho, São Paulo, v. 10, n. 2, p. 35-45, 2007.

RENTERÍA, E. Salud, bienestar y mundo del trabajo: entre lo normativo, los riesgos, y la coexistencia de realidades. In: COSTA, M.; ZANATTA, J. (Org.). Psicologia da Saúde: discussões temáticas. Campo Grande, MS: UCDB, 2016. p. 171-92.

RENTERÍA, E. Desarrollo de la empleabilidad como estrategia para las organizaciones: limitaciones, posibilidades e implicaciones para las personas. Revista Aristeo, n. 2, p. 69-90, 2012.

RENTERÍA, E. De Recursos Humanos a la Psicología Organizacional y del Trabajo: reflexiones a la luz de las realidades actuales del mundo del trabajo. In: AGUILAR, M. C.; RENTERÍA, e. Psicología del Trabajo y de las Organizaciones: reflexiones y experiencias de investigación. Bogotá: Editora Universidad Santo Tomás, 2009. p. 25-52.

RENTERÍA, E. Empregabilidade: versões e implicações. Uma leitura desde a Psicologia Social. 2008. Tese (Doutorado em Psicologia) - Universidade de São Paulo (USP), São Paulo, 2008. Disponível em: <http:// www.teses.usp.br/teses/disponiveis/47/47134/tde-12022009-143157/pt-br.php>. Acesso em: 10 nov. 2016.

RENTERÍA, E.; MALVEZZI, S. Empleabilidad, cambios y exigencias psicosociales en el trabajo. Universitas Psychologica, Bogotá, Colômbia, v. 7, n. 2, p. 319-34, maio/ago. 2008. Disponível em: <http://www.scielo. org.co/scielo.php?script=sci_arttext\&pid=S1657-92672008000200002\&lng=en\&nrm=iso>. Acesso em: 20 dez. 2016.

RIOS, I.; TEIXEIRA, J. E. Projeto Rhodia de desenvolvimento da empregabilidade. In: CASALI, A.; RIOS, I.; TEIXEIRA, J. E.; CORTELA, M. S. (Org.). Empregabilidade e educação: novos caminhos no mundo do trabalho. São Paulo: EDUC, 1997. 
ROIEK, R. S.; BULGACOV, S. D. Declínio organizacional e processo estratégico. Rio de Janeiro, Associação Nacional dos Programas de Pós-graduação em Administração (Anpad), 1999. Disponível em: <http:// www.anpad.org.br/admin/pdf/enanpad1999-ae-29.pdf>. Acesso em: 25 jul. 2016.

ROSE, V.; HARRIS, E. From efficacy to effectiveness: case studies in unemployment research. Journal of Public Health, v. 26, n. 3, p. 297-302, 2004.

SALAMA, A. O uso da biografia de uma organização como método de pesquisa para a investigação do desenvolvimento organizacional. Revista de Administração Pública, Rio de Janeiro, v. 28, n. 1, p. p. 34-42, jan./mar. 1994.

SALLES, L. F. Como as empresas brasileiras da indústria têxtil lidam com o declínio? Um estudo multicaso das ações estratégicas. 2015. Dissertação (Mestrado em Administração) - Universidade Nove de Julho (UNINOVE), São Paulo, 2015.

SERRA, F.; FERREIRA, M.; ALMEIDA, M. Organizational decline: a yet largely neglected topic in organizacional studies. Managemente Research, v. 11, n. 2, p. 133-56, 2013.

THIRY-CHERQUES, H. R. Administrando a sobrevivência: indicadores de declínio de revitalização organizacional em ambiente adverso. Revista de Administração Pública, Rio de Janeiro, v. 25, n. 4, p. 177-86, out./dez. 1991.

TORRES, A. P. Estudo do declínio em uma empresa brasileira: o caso da gradiente eletrônica. 2010. Tese (Doutorado em Engenharia de Produção)- Universidade Federal de Santa Catarina (UFSC), Florianópolis, 2010.

TORRES, A. P. et al. O declínio das grandes empresas brasileiras. Center of Research in International Business \& Strategy, Working Paper n. 26. 2008. Disponível em: <http://globadvantage.ipleiria.pt/files/2008/10/ working_paper-26_globadvantage.pdf>. Acesso em: jan. 2016.

VASCONCELOS, E. F. Declínio do Projeto Organizacional UFN III: explorando o significado da experiência entre os atores. 2016. Tese (Doutorado em Psicologia)- Universidade Católica Dom Bosco (UCDB)- Campo Grande, MS, 2016.

VASCONCELOS, Y. L. Mapas explicativos da insolvência em nível falimentar: as perspectivas de gestores, consultores e acadêmicos. 2007. Tese (Doutorado em Administração) - Universidade Federal da Bahia (UFBA), Salvador, 2007.

VESGA, J. J. El contrato psicológico: una propuesta de lectura en el marco de las relaciones de trabajo. 2016. Tese (Doutorado em Psicologia)- Instituto de Psicología, Universidad del Valle, Cali, Colômbia, 2016.

WEITZEL, W.; JONSSON, E. Decline in organizations: a literature integration and extension. Administrative Science Quarterly, v. 34, n. 1, p. 91-109, mar. 1989.

WITTE, H.; HOOGE, J.; VANBELLE, E. Do the long-term unemployed adapt to unemployment. Romanian Journal of Applied Psychology, v. 12, n. 1, p. 8-14, 2010.

ZANELLI, J. C. Mudança organizacional. In: BENDASSOLLI, P. F.; BORGES-ANDRADE, J. E. (Org.). Dicionário de psicologia do trabalho e das organizações. São Paulo: Casa do Psicólogo, 2015. p. 463-72.

\section{Sobre os autores:}

Eveli Freire Vasconcelos: Possui graduação, mestrado e doutorado em Psicologia pela UCDB. Atua como docente e supervisora de estágio Básico e Específico no Curso de Graduação em Psicologia. Tem experiência em Psicologia, Organizações e Trabalho, atuando principalmente em temas da área: gestão de pessoas, comportamento organizacional.E-mail: evelivasconcelos@yahoo.com.br

José Carlos Zanelli: Possui graduação em Psicologia pela Universidade de Brasília, especialização em Psicologia Organizacional e do Trabalho pelo Instituto Sedes Sapientiae, mestrado em 
Psicologia Social das Organizações pelo Instituto Metodista de Ensino Superior de São Bernardo do Campo, doutorado em Educação pela Universidade Estadual de Campinas, pós-doutorado pela Universidade de São Paulo, com foco nas ações de uma gestão estratégica, pós-doutorado pela Pontifícia Universidade Católica de Campinas, com foco nas teorias e tratamento do estresse nas organizações de trabalho, e pós-doutorado pelo Instituto Português de Oncologia do Porto, com foco na gestão preventiva de riscos psicossociais. Professor e pesquisador do Programa de Pós-Graduação em Administração e faz parte do núcleo stricto sensu em Psicologia da Faculdade Meridional (IMED). É Diretor do Instituto Zanelli - Saúde e Produtividade. É conferencista na área de interface da Psicologia com a Administração E-mail: jczanelli@terra.com.br

Erico Renteria: Possui graduação em Psicología - Universidad Del Valle, mestrado em Psicologia (Psicologia Social) pela Pontifícia Universidade Católica de São Paulo e doutorado em Psicologia Social pela Universidade de São Paulo. Diretor do Grupo de Pesquisa em Psicologia Organizacional e do Trabalho, Professor Titular, Instituto de Psicologia, Universidad del Valle, Cali - Colômbia. Tem sido Subdiretor de Pesquisa e pós-graduação do Instituto de Psicologia da Universidad del Valle. Professor convidado na Universidade de São Paulo, Universidade de Brasília, Universidade Estadual de Londrina, Universidade Católica Dom Bosco, e em outras universidades de Porto Rico, Argentina e Chile. Co-diretor de teses doutorais no departamento de Psicologia Social da Universidade Autônoma de Barcelona. Avaliador do Ministério de Educação Nacional da Colômbia para acreditação de alta qualidade de programas acadêmicos de graduação e pós-graduação. Áreas de atuação em Psicologia do Trabalho e Psicologia Organizacional, processos humanos no trabalho, formas organizativas, processos organizacionais, métodos e abordagens qualitativos, e Psicologia Social. E-mail: erico.renteria@correounivalle.edu.co

Márcio Luís Costa: Graduação em Filosofia pela FUCMT, hoje UCDB. Mestrado e Doutorado em Filosofia na Facultad de Filosofía y Letras da Universidad Nacional Autónoma de México, México, DF. Professor na Graduação em Filosofia e no Programa de Mestrado e Doutorado em Psicologia da UCDB. Coordena o Grupo de Pesquisa Modelos Histórico-epistemológicos e Produção de Saúde, com registro no CNPQ e Certificação da UCDB. Coordena o Grupo de Estudos A Fenomenologia na Pesquisa no campo da Psicologia e Saúde, vinculado ao Laboratório de Psicologia da Saúde, políticas da cognição e da subjetividade do Mestrado e Doutorado em Psicologia e ao programa de atividades complementares dos Cursos de Graduação em Filosofia e em Psicologia da UCDB. Desenvolve também pesquisas e orienta em Representações Sociais e Fenomenologia no Mestrado e Doutorado em Psicologia da UCDB. Atua como Coordenador do Programa de Mestrado e Doutorado em Psicologia da UCDB. Integra, como membro permanente e foi reeleito como Presidente do Comitê de Ética em Pesquisa da UCDB, mandato 2016-2018. Colabora como Professor convidado na disciplina de Epistemologia no Doutorado em Educação da UCDB.

E-mail: marcius1962@gmail.com 
